\title{
EFEITO dA ÁREA E dA PRODUTIVIdAdE NA PRODUÇÃo DE CELULOSE NO BRASIL ${ }^{1}$
}

\author{
Kaio Henrique Adame de Carvalho², Márcio Lopes da Silva e Naisy Silva Soares ${ }^{4}$
}

\begin{abstract}
RESUMO - O presente trabalho teve por objetivo estudar a evolução tecnológica da produção de madeira para celulose, para tanto, a produção de celulose de fibra curta derivada do eucalipto foi decomposta em efeito área e efeito produtividade. Para isso foi usado o modelo shift-share com o qual se verificou qual dessas duas variáveis mais contribuiu para a evolução na produção de celulose no país nos últimos anos. Foram avaliados os seguintes períodos: 1960 a 1970; 1970 a 1980; 1980 a 1990; 1990 a 2000; 2000 a 2007 e 1960 a 2007. No geral, foi observado que 1960 a 2007 o principal fator que explicou o crescimento da produção de celulose foi a produtividade, porém o valor baixo para o efeito área foi devido a sua expansão só ter começado na década de 90. Também foi observado que os reflorestamentos no Brasil são muito recentes quando comparado a outros países, mesmo assim o setor de celulose brasileiro conseguiu se tornar competitivo tanto no mercado nacional quanto no internacional.
\end{abstract}

Palavras-chave: Celulose de fibra curta, Shift-share e Área plantada.

\section{EFFECT OF AREA AND PRODUCTIVITY IN PULP PRODUCTION IN BRAZIL}

\begin{abstract}
The objective of this work was to study the technological production of pulpwood.Therefore, production of hardwood pulp derived from eucalyptus effect was broken down into area and productivity effects. For this purpose, we used the shift-share model with which was found that these two variables contributed most to the trend in pulp production in the country in recent years. The following periods were evaluated: 1960 to 1970; 1970 to 1980; 1980 to 1990; 1990 to 2000; 2000 to 2007 and 1960 to 2007. Overall, it was observed that from 1960 to 2007, the main factor that explained the growth of pulp production was the productivity, but the low value for the area effect was due to expansion that started only in the 1990s. We also found that the planted forests in Brazil are very recent when compared to other countries, although the Brazilian pulp industry has managed to become competitive in both within the country and abroad.
\end{abstract}

Keywords: Hardwood pulp, Shift-share and Planted area.

\section{INTRODUÇÃO}

O segmento de celulose e papel tem-se destacado como o mais importante do setor florestal e como um dos mais bem-sucedidos da economia brasileira, contribuindo significativamente para o seu desenvolvimento em termos de geração de renda, emprego, imposto e divisas.
Em 2007, o Brasil foi o sexto maior produtor de celulose do mundo, porém, quando se fala em celulose de eucalipto, passa para a primeira posição. Já em 2008 o país exportou US $\$ 5,8$ bilhões de dólares, apresentando um saldo comercial de US $\$ 4,1$ bilhões, o que corresponde a $16,6 \%$ do saldo da Balança Comercial do país. Para o mesmo ano, o segmento pagou em impostos $\mathrm{R} \$ 2,2$

\footnotetext{
${ }^{1}$ Recebido em 02.12.2009 aceito para publicação em 04.06.2012.

${ }^{2}$ Pós-Graduação em Ciência Florestal na Universidade Federal de Viçosa, UFV, Brasil. E-mail: <kaio_adame@ hotmail.com>.

${ }^{3}$ Universidade Federal de Viçosa, Departamento de Engenharia Florestal. E-mail: <marlosil@ufv.br>.

${ }^{4}$ Universidade Estadual de Santa Cruz, Departamento de Ciências Econômicas. E-mail: <naisysilva@ yahoo.com.br>.
} 
milhões de reais, além de gerar 114 mil empregos diretos e 570 mil indiretos (BRACELPA, 2008). O Brasil está entre os maiores exportadores de celulose do mundo. Os principais destinos das exportações nacionais são: Estados Unidos, Japão, Itália, Alemanha, França, Inglaterra e Bélgica (BRACELPA, 2008).

O segmento de celulose é altamente globalizado, intensivo em capital, e a maturação dos seus investimentos ocorre no longo prazo (MOURA, 2008). Todas as companhias de celulose são verticalizadas desde a base florestal, sendo a maioria delas especializada em determinado tipo de fibra. Essas fibras podem ser divididas em dois grupos: a "linha marrom" (celulose fibra longa, papéis de embalagem, caixas de papelão ondulado e sacos multifolhados); e a "linha branca" (celulose fibra curta, papéis de imprimir/escrever, cartões e sanitários) (BNDES, 1996).

Apesar de o Brasil apresentar infraestrutura inadequada de serviços sociais, transporte, financiamento com taxas de juros elevadas, entre outros, as empresas de celulose conseguem ser competitivas. Isso se deve à alta produtividade dos reflorestamentos, em razão das condições climáticas favoráveis do país, que conta ainda com um ciclo rápido de crescimento e produção de baixo custo (PIZZOL; BACHA, 1998).

Valverde et al. (2006), ao estudarem o desempenho das exportações de celulose no país, observaram que o Brasil vem ganhando competitividade no mercado internacional ao longo dos anos, sendo as taxas de crescimento de exportações as maiores entre todos os países. Com isso, acredita-se que, em breve, o Brasil poderá ser o maior exportador de celulose em termos de valor exportado.

A maioria dos países produtores de celulose utiliza como matéria-prima apenas dois gêneros florestais: Eucalyptus e Pinus. No ano de 2007, por exemplo, a produção nacional de celulose de eucalipto foi de 10.001.444 toneladas e de pinus, de 1.474.842 toneladas (BRACELPA, 2008).

Segundo Soares et al. (2009), as exportações nacionais de celulose são mais sensíveis às variações na quantidade produzida internamente, uma vez que aumento de $1 \%$ nessa variável provoca acréscimo de $4,48 \%$ nas exportações nacionais do produto, coeteris paribus.

Como a produtividade das florestas de eucalipto e a área plantada no Brasil são importantes para o crescimento da produção nacional de celulose (SOARES et al., 2009), fazem-se necessário estudar os efeitos da área plantada e da produtividade no Brasil sobre a produção de celulose, pois estudos nesse sentido são de grande importância para o planejamento da produção, comercialização, previsão e formulação de políticas para o segmento e, consequentemente, para melhorar o desempenho da economia brasileira.

Portanto, este trabalho teve como objetivo estudar a evolução do segmento de celulose de fibra curta no Brasil, utilizando-se do modelo shift-share, que decompõe a produção de celulose em efeito área e efeito produtividade, de modo a verificar qual dessas variáveis mais contribuiu para a variação da produção de celulose de fibra curta no país nos últimos anos.

\section{MATERIAL E MÉTODOS:}

\subsection{Referencial Analítico}

Para decompor a produção de celulose em efeitos área e produtividade, foi utilizado o modelo shift-share, também conhecido como "diferencial-estrutural". Esse modelo visa explicar o comportamento do segmento de celulose através dos vários fatores responsáveis pela produção.

Muitos estudos já foram feitos utilizando esse modelo, principalmente no setor agrícola. Alves e Shikita (2001) analisaram as fontes de crescimento das culturas agrícolas do Estado do Paraná. Esses autores concluíram que o efeito do rendimento das culturas foi o fator mais importante para explicar o crescimento da produção agrícola no Estado no período de 1981 a 1999.

Já Almeida (2003) analisou o crescimento da orizicultura no Estado do Mato Grosso. Através deste estudo, foi observado que a cultura do arroz foi a que obteve menor crescimento de produção no período compreendido entre os anos de 1980 a 2001, tendo sofrido redução em sua área de produção.

Filgueiras (2002) analisou o crescimento agrícola no Estado do Pará, confrontando seus resultados com as políticas públicas adotadas pelo Estado. Com este estudo, esse autor demonstrou que a implantação das políticas públicas adotadas pelo Estado foi crucial para o setor agrícola.

Apesar de o modelo shift-share ser bastante difundido no setor agrícola, o mesmo não ocorre no setor florestal em razão, principalmente, da dificuldade de se conseguirem dados históricos sobre o setor. 
Por meio do modelo shift-share, podem-se decompor as fontes de crescimento do segmento de celulose em três fatores, efeito área, produtividade e localização geográfica. De acordo com Filgueiras (2002), esses efeitos podem ser descritos conforme mostrado nos tópicos subsequentes.

O efeito área resulta das variações da produção quando varia a área plantada da essência florestal, considerando que os fatores produtividade e localização geográfica permaneçam constantes. Esse efeito indica as variações da expansão florestal, quebra de barreiras agrícolas e substituição de culturas.

O efeito produtividade apresenta a intensificação dos meios de produção, mantidas as demais variáveis constantes. Engloba melhoria de tecnologia, melhoria de clones e sementes, queda de mortalidade e também apresenta o incremento da produção por unidade de área.

O efeito localização geográfica reflete as variações ocorridas devido às vantagens locacionais. Isso ocorre quando as essências florestais passam a ser cultivadas em outras localidades, sendo as antigas localidades utilizadas para outros fins, mantendo os demais efeitos constantes (ALMEIDA, 2003).

Neste trabalho, porém, tomou-se como referência o estudo de Reis e Campos (1998), que modificaram o modelo para analisar a influência da taxa de câmbio no preço do cacau. Esses autores decompuseram o preço do cacau no Brasil em efeito câmbio e efeito dólar.

\subsection{Decomposição em efeitos área e produtividade para produção de celulose de fibra curta.}

Ressalta-se que para analisar a produção de celulose os modelos originais devem ser modificados. Neste estudo, utilizou-se o fator 4 como taxa de conversão de $\mathrm{m}^{3}$ de madeira para tonelada de celulose, conforme observado na expressão 1. Ressalta-se, ainda, que os dados de áreas utilizados se referem às áreas cortadas anualmente e não à área plantada, visto que a área cortada em determinado ano está ligada com a produtividade desse mesmo ano, enquanto a área plantada só terá produção futuramente. Outro ponto importante é que os dados de área e produtividade são somente dos povoamentos destinados ao segmento de celulose de fibra curta.
A expressão (1) apresenta a produção de celulose em toneladas, em um dado período "t $\mathrm{t}$ ";

$$
P C_{t}=\frac{A_{t} \times P_{t}}{4}
$$

em que:

$P C_{t}=$ produção de celulose em toneladas;

$A^{t}=$ área cortada em ha;

$P_{t}=$ produtividade média das florestas de eucalipto ( $\left.\mathrm{m}^{3} / \mathrm{ha} / \mathrm{ano}\right)$;

4 = fator de transformação de metro cúbico $\left(\mathrm{m}^{3}\right)$ de madeira para tonelada $(\mathrm{T})$ de celulose.

Os períodos iniciais e finais são indicados pelos índices " 0 " e "t", respectivamente.

De forma idêntica à expressão (1), a expressão (2) apresenta a produção em toneladas, no período inicial " 0 ";

$$
P C_{0}=\frac{A_{0} \times E_{0}}{4}
$$

A expressão (3) apresenta a variação da produção, em toneladas, quando varia somente a área plantada;

$$
P C_{t}^{A}=\frac{A_{t} \times P_{0}}{4}
$$

A expressão (4) apresenta a variação da produção em toneladas quando somente a produtividade varia;

$$
P C_{t}^{P}=\frac{A_{0} \times P_{t}}{4}
$$

A mudança na produção, em toneladas, entre o período “0” e o período "t", é expressa por:

$$
P C_{t}-P C_{0}=\left(P C_{t}^{A}-P C_{0}\right)+\left(P C_{t}-P C_{t}^{A}\right)
$$

em que:

$P C_{t}-P C_{0}=$ variação total da produção em toneladas; $P C_{t}^{A}-P C_{0}=$ efeito área cortada em hectares;

$P C_{t}-P C_{t}^{A}=$ efeito produtividade.

Segundo Igreja (citado por CAMPOS, 1991), os efeitos explicativos podem ser apresentados individualmente na forma de taxas de crescimento que, somados, resultarão na taxa média anual de crescimento.

Revista Árvore, Viçosa-MG, v.36, n.6, p.1119-1128, 2012 
Então, usando-se a expressão (5) e multiplicando-se ambos os lados dessa expressão por:

tem-se:

$$
\frac{1}{\left(P C_{t}-P C_{0}\right)}
$$

$$
1=\frac{\left(P C_{t}^{A}-P C_{0}\right)}{\left(P C_{t}-P C_{0}\right)}+\frac{\left(P C_{t}-P C_{t}^{A}\right)}{\left(P C_{t}-P C_{0}\right)}
$$

A seguir multiplicando-se ambos os lados da identidade (6) por

$$
r=\left(\sqrt[t]{P C_{t} / P C_{0}}-1\right) \times 100
$$

em que:

$\mathrm{r}=$ taxa média anual de variação da produção em toneladas (efeito total),

obtém-se:

em que:

$$
r=\frac{\left(P C_{t}^{A}-P C_{0}\right)}{\left(P C_{t}-P C_{0}\right)} \cdot r+\frac{\left(P C_{t}-P C_{t}^{A}\right)}{\left(P C_{t}-P C_{0}\right)} \cdot r
$$

$\frac{\left(P C_{t}^{A}-P C_{0}\right)}{\left(P C_{t}-P C_{0}\right)} \cdot r=$ efeito área cortada em hectares, expresso em porcentagem ano ;

$\frac{\left(P C_{t}-P C_{t}^{A}\right)}{\left(P C_{t}-P C_{0}\right)} \cdot r=$ efeito produtividade, expresso em porcentagem ano.

Para alguns anos não estavam disponíveis dados reais da produtividade de eucalipto. Para contornar essa situação, foi utilizado um modelo, desenvolvido por Souza (1999), que estima sua produtividade para determinado ano. Essa produtividade foi calculada em metro estéreo por hectare e depois convertido para metro cúbico por hectare utilizando um fator de 0,66.

em que:

$$
Y_{n}=\frac{Y^{*}\left[1+j(1-u)^{n t}\right]^{n t}}{7}
$$

$Y_{n}=$ produtividade em st/ha no ano $\mathrm{n}$

$Y=$ produtividade $\mathrm{em} \mathrm{st/ha} \mathrm{no} \mathrm{ano} \mathrm{inicial}$

$j=$ taxa de crescimento da produtividade, $15 \%(0,15)$

$u=$ índice moderador do modelo evitando números irreais, $2,3 \%(0,023)$

$n t=$ Tempo decorrente entre $\mathrm{Y}$ e Yn

\subsection{Fontes de Dados:}

A área estudada compreendeu todo o território nacional, com foco nas áreas que possuem plantios de eucalipto para produção de celulose.

Os dados essenciais para o desenvolvimento da pesquisa são: produtividade do eucalipto ao longo dos anos e produção de celulose. Estes foram obtidos dos relatórios estatísticos da BRACELPA. A área anualmente cortada para produção de celulose foi obtida de forma indireta pela equação 9.

em que:

$$
A c=\frac{P C_{t} * 4}{P_{t}}
$$

$A c=$ área cortada anualmente por ano em hectares; $P C_{t}=$ produção de celulose em toneladas;

$P_{t}=$ produtividade média dos plantios de eucalipto ( $\left.\mathrm{m}^{3} / \mathrm{ha} / \mathrm{ano}\right)$.

\section{RESULTADOS}

Nesta sessão são apresentados os resultados com base no modelo shift-share, para os seguintes períodos: 1960-1970; 1970-1980; 1980-1990; 1990-2000; 2000-2007; e 1960-2007 (Tabela 1).

\section{DISCUSSÕES:}

\subsection{0-1970:}

A taxa média de crescimento da produção nesse período foi de $12 \%$ ao ano em razão, principalmente, do efeito produtividade, já que a área plantada nesse

Tabela 1 - Decomposição da taxa média anual de crescimento da produção nacional de celulose de eucalipto em efeito área e produtividade.

Table 1 -Decomposition of average annual growth of domestic production of eucalyptus pulp in effect area and productivity.

\begin{tabular}{cccc}
\hline Período & $\begin{array}{c}\text { Taxa media } \\
\text { de crescimento } \\
\text { Produtividade }(\%)\end{array}$ & $\begin{array}{c}\text { Efeito da } \\
\text { produção } \\
(\%)\end{array}$ & $\begin{array}{c}\text { Efeito } \\
\text { área }(\%)\end{array}$ \\
\hline $1960-1970$ & 12,00 & 0,00 & 12,00 \\
$1970-1980$ & 18,55 & 3,84 & 14,71 \\
$1980-1990$ & 2,61 & 1,32 & 1,29 \\
$1990-2000$ & 7,29 & 5,45 & 1,84 \\
$2000-2007$ & 8,80 & 4,00 & 4,80 \\
$1960-2007$ & 9,87 & 0,57 & 9,30 \\
\hline
\end{tabular}

Fonte: Dados da Pesquisa.

Revista Árvore, Viçosa-MG, v.36, n.6, p.1119-1128, 2012 
período foi muito pequena. Os reflorestamentos foram implantados somente a partir de 1966, quando começaram os incentivos fiscais. Antes disso, as empresas de celulose obtinham madeira comprada de empreiteiras (SOTO, 1992). Segundo esse mesmo autor, no final da década de 1960 a capacidade de produção de fibras curtas das empresas de celulose triplicou em relação a 1961. Assim, de 1966 a 1970, as indústrias plantaram o dobro do que tinham feito antes da implantação do código. Esses plantios, em mais de $80 \%$ dos casos, foram feitos através dos incentivos fiscais, o que vem mostrar a importância destes para a configuração atual do setor florestal brasileiro.

No final da década de 1960, o Banco Nacional do Desenvolvimento Econômico e Social (BNDES) passou a investir mais no segmento de celulose. A proliferação de fábricas de celulose e papel levou à necessidade de conhecer o universo de empresas que formavam o segmento no Brasil. Nesse contexto, a Associação Nacional dos Fabricantes de Papel e Celulose (ANFPC) propôs ao BNDES o financiamento de um estudo que diagnosticasse o "estado da arte" da cadeia produtiva de papel no país e a viabilidade de desenvolver uma indústria nacional de celulose e papel. Em outubro de 1968, o Conselho de Administração do BNDES aprovou a Decisão 196/68, que fixava novos parâmetros para o apoio ao setor florestal. A partir daí, a instituição passou a contemplar projetos de implantação e expansão de unidades produtoras de papel. A decisão estabelecia, também, foi que a colaboração financeira ficava condicionada à demonstração de que a empresa dispunha de suprimento próprio de fibras, equivalente a, no mínimo, $50 \%$ das necessidades calculadas (JUVENAL; MATTOS, 2002).

Observa-se que, apesar de a taxa de crescimento desse período ser devida apenas à produtividade, a área plantada contribui a partir de 1966 mais significativamente. O BNDES exigia que as indústrias de celulose tivessem matéria-prima própria para aprovar seus financiamentos, além do Código Florestal de 1966, que exigia que as indústrias tivessem seus próprios plantios

\section{2. $1970-1980$}

De 1970 a 1980, a taxa média de crescimento da produção de celulose foi de $18,55 \%$ ao ano, e o efeito produtividade foi o maior responsável por essa taxa de crescimento (Tabela 1 ).
No ano de 1970, a relação entre fibra curta e fibra longa na produção nacional de celulose inverteu-se quando comparado com 1950. A produção de fibra longa caiu de $96 \%$ para $42 \%$, enquanto a fibra curta cresceu de $4 \%$ para $58 \%$ (ZAEYEN, 1986 citado por SOTO, 1992).

No período de 1971-74, a indústria de celulose triplicou os reflorestamentos realizados em relação a 1967-70. Esse valor foi de 158.000 ha, o que representa a participação de apenas $13 \%$ da área total reflorestada no país. Já a partir de 1974 foi quando se deu a maior expansão das áreas reflorestadas.

Também no início de 1974, o Conselho do BNDE (antigo BNDES) aprovou o Plano de Ação para o período 1974 1978, o qual estabelecia que os projetos que tivessem como objetivo a exportação teriam estímulo prioritário. Assim, surgia o II Plano Nacional do Desenvolvimento (PND), em que foi elaborado o I Programa Nacional de Papel e Celulose (I PNPC). O objetivo era alcançar a autossuficiência, tanto em papel quanto em celulose, prevendo, para esta última, a geração de excedentes exportáveis (HILGEMBERG; BACHA, 2001). Observando a Figura 1, nota-se que a partir de 1978 houve incremento da produção de celulose de fibra curta.

No final da década de 1960, a eucaliptocultura expandiu-se para outras regiões. Nessa década surgiu o primeiro grande problema da cultura, o cancro, causado pelo fungo Cryphonectria cubensis Burner (Hodges). Nessa época também descobriu-se o grande potencial de híbridos de E. grandis x E. urophylla, que associavam resistência ao cancro e características agronômicas. Esse fato impulsionou os estudos de propagação vegetativa e, em 1979, foi instalado o primeiro plantio comercial via propagação vegetativa, de cerca de 1.000 ha, em Aracruz, no Estado do Espírito Santo (CARVALHO, 2000).

O melhoramento genético e o nível tecnológico dos plantios foram essenciais para o desenvolvimento das empresas de celulose e papel durante aquela década. O crescimento da produção de celulose, nesse período, foi o maior observado, com 18,55\%, sendo $14,71 \%$ devido ao fator produtividade e $3,84 \%$ ao fator área. Observou-se que os incentivos fiscais foram de fundamental importância para esse crescimento, bem como as políticas públicas. A área plantada cresceu muito, porém as melhorias nos aspectos silviculturais foram os principais fatores que contribuíram para esse crescimento.

Revista Árvore, Viçosa-MG, v.36, n.6, p.1119-1128, 2012 


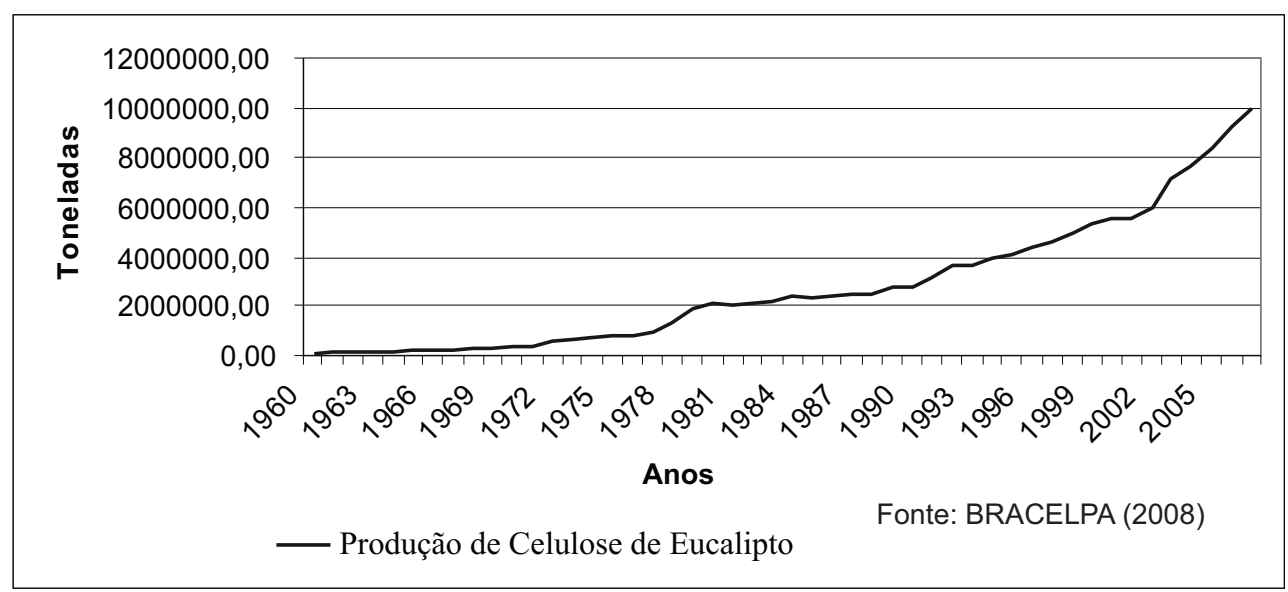

Figura 1 - Evolução da produção nacional de celulose de fibra curta.

Figure 1 - Evolution of the national production of hardwood pulp.

\section{3. $1980-1990$}

Considerando o período de 1980 a 1990, observou-se que a taxa média de crescimento da produção de celulose foi muito baixa, da ordem de $2,61 \%$ ao ano (Tabela 1 ). Essa condição pode estar relacionada com a estagnação econômica do Brasil nesse período.

A década de 1980 foi marcada por uma crise na economia brasileira. Essa crise começou rompendo os padrões de financiamento externo e culminou com a falência das finanças públicas. Nesse período, o país passou por forte recessão e por um quadro inflacionário crônico, que afetou os investimentos e desempenho da economia em geral (SOTO, 1992). Entretanto, apesar da crise, o BNDES continuou investindo no setor florestal. Na segunda metade da década, o banco iniciou um novo ciclo de investimentos na modernização e ampliação da capacidade produtiva da indústria. Em 1987 surge o II Programa Nacional de Papel e Celulose (II PNPC), que previa investimentos de cerca de US\$ 9,6 bilhões para o período de 1987 a 1995 (HILGEMBERG; BACHA, 2001).

Segundo Montebello (2006), na década de 1980 houve progressos tecnológicos na silvicultura no Brasil, principalmente nos quesitos de melhoramento genético e produção de mudas por sementes. Também ocorreu melhoria nos substratos e recipientes utilizados para a produção de mudas.

O período de 1986-92 representa a consolidação da indústria de celulose e papel. Nessa fase, mais que projetos de implantação, realizaram-se investimentos em modernização e em ganho de produtividade. Além disso, houve maior preocupação com a profissionalização da gestão das empresas. A abertura de capital, apoiada técnica e financeiramente pelo BNDES, passou a ser analisada com menos desconfiança pelos controladores das empresas (JUVENAL; MATTOS, 2002). Segundo Hilgemberg e Bacha (2001), foi nessa década que as empresas se tornaram autossuficientes na produção de matéria-prima florestal.

Para essa década, a taxa média anual do crescimento da produção de celulose de eucalipto foi de 2,61\%, sendo $1,32 \%$ devido à área e 1,29\% à produtividade. A partir dessa década, observou-se que o fator área passa a apresentar um efeito mais significativo que nas décadas anteriores.

Devido à crise econômica e ao término dos incentivos fiscais em 1986, essa taxa foi bem menor, se comparada às outras décadas. Porém, foi a partir dessa década que as empresas passaram a ter maior domínio de seus reflorestamentos, aumentando seus plantios e investindo em tecnologia. Isso pode explicar a pequena diferença entre efeito área e efeito produtividade no período.

\section{4. $1990-2000$}

Na década de 1990, a produção brasileira de celulose voltou a crescer em relação à década anterior em razão, principalmente, do crescimento da área plantada. Nesse período, 5,45\% do crescimento foi devido à área e 1,84\% à produtividade, como pode ser observado na Tabela

Revista Árvore, Viçosa-MG, v.36, n.6, p.1119-1128, 2012 
1. A produtividade teve incremento significativo devido, principalmente, ao avanço tecnológico dos tratos silviculturais.

A área reflorestada aumentou consideravelmente durante a década de 1990. Dados da BRACELPA apontam que, em 1990, os reflorestamentos com eucalipto totalizavam 7.331,9 ha. Em 2000, esses valores atingiram $39.866,9$ ha.

Notou-se, também, que essa foi a única década em que o efeito área foi maior que o efeito produtividade, o que reflete o amadurecimento na expansão do segmento de celulose nesse período. As principais indústrias passaram a produzir visando ao mercado internacional, o que contribuiu com incremento nas exportações, conforme Figura 2. Segundo Juvenal e Mattos (2002), a parceria do BNDES com o segmento de celulose e papel também amadureceu na década de 1990. As políticas de estímulo ao crescimento da produção e à adoção de práticas empresariais compatíveis com as exigências sociais e mercadológicas, tônica do período 1952-92, deram lugar às inovações financeiras e ao desenvolvimento de mecanismos que permitissem ao segmento enfrentar a competição internacional em condições de igualdade.

\section{5. $2000-2007$}

No período de 2000 a 2007, a produção de celulose cresceu em média $8,80 \%$ ao ano. O efeito da área contribuiu com $4,0 \%$ do crescimento observado e a produtividade, com $4,80 \%$. Assim, a produtividade foi, novamente, o principal fator a influenciar esse crescimento, apesar de em escala muito menor, em comparação com as décadas de 1960, 70 e 80. Mesmo a área plantada tendo aumentado nessa época, esses fatores serão utilizados no futuro, já que o eucalipto é cortado com 7 anos de idade, em média. Isso pode explicar a menor influência da área sobre a taxa de crescimento da produção de celulose no Brasil, no período. Também, observando a Figura 3, nota-se que, a partir dos anos 2000 , a produtividade dos reflorestamentos voltou a crescer.

"A partir de 1998, a atuação do BNDES e sua capacidade de acompanhar as necessidades do mercado foram importantes para o forte movimento de consolidação que o segmento de celulose e papel viveu no Brasil, acompanhando a tendência mundial. As empresas nacionais buscaram aumentar a escala produtiva e as sinergias operacionais, de forma a possibilitar melhor posição no mercado" (JUVENAL; MATTOS, 2002).

Segundo Montebello (2006), as inovações tecnológicas desse período são uma continuação da década anterior. Todos os fatores que foram relevantes na década de 1990 também o foram nos anos 2000. Porém, as inovações tecnológicas no controle, a matocompetição e a adubação foram as mais importantes. Também, foi nesse período que a utilização dos clones de eucalipto teve relevância no crescimento da

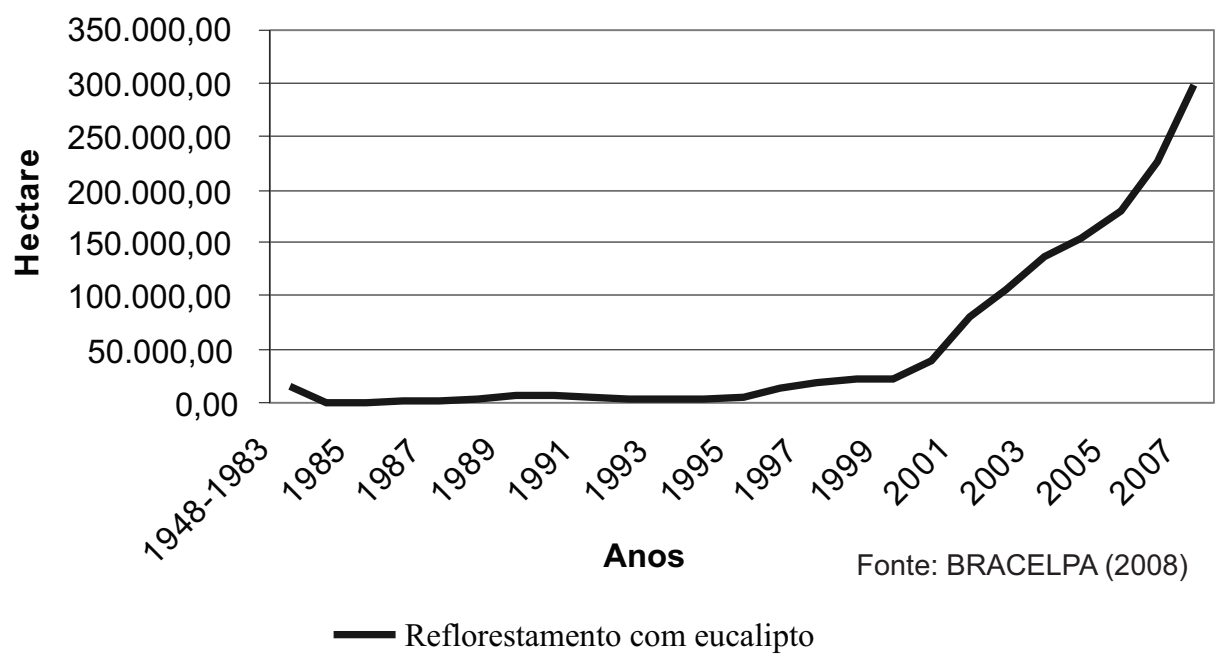

Figura 2 - Evolução dos reflorestamentos de eucalipto feitos pelo segmento de celulose e papel no Brasil . Figure 2 - Evolution of eucalyptus's reforestation made by pulp and paper segment in Brazil. 


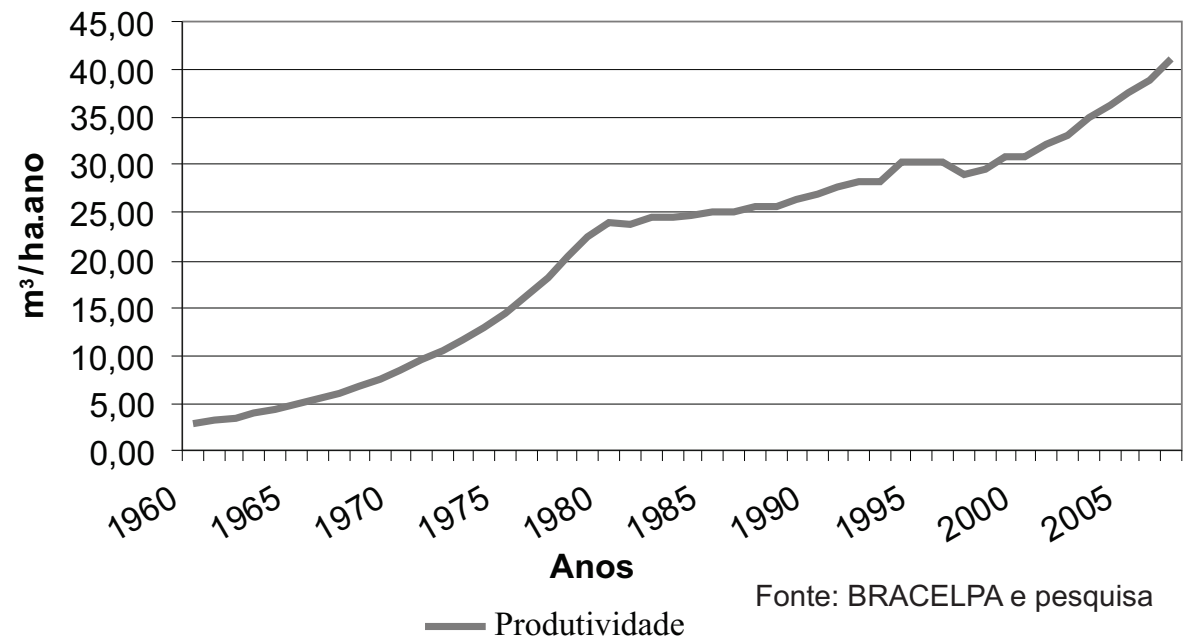

Figura 3 - Evolução da produtividade brasileira das florestas de eucalipto para produção de celulose. Figure 3 -Evolution of Brazilian productivity of eucalyptus forest for pulp production.

produtividade, conforme pode ser observado na Figura 3. Já as inovações nos processos mecanizados também foram relevantes, visto que reduzem custos e aumentam a competitividade. Outro aspecto importante foi que, nesse período, houve grande investimento em qualidade e controle de viveiros.

Nesse período, observou-se que a área plantada também cresceu. Em 2007, a área plantada com eucalipto era de 297.861,7 ha, enquanto nos anos 2000, de apenas $39.866,9$ ha. $O$ aumento foi de 7,47 vezes, um crescimento bem maior quando comparado com o da década de 1990, conforme observado na Figura 2.

\section{6. $1960-2007$}

De maneira geral, a produção de celulose apresentou crescimento médio anual de $9,87 \%$, sendo $0,57 \%$ devido à área e 9,30\% à produtividade. Esse valor baixo para o efeito área é explicado pelo fato de essa variável ter sofrido expansão maior a partir da década de 1990, conforme observado na Figura 2.

Os avanços tecnológicos podem ser medidos de acordo com a evolução da produtividade. Observando a Figura 3, nota-se que o aumento da produtividade teve três fases: a primeira de 1960 a 1980, em que os avanços genéticos foram de extrema importância; a segunda dos anos de 1980 a 2000, em que se notou avanço nas práticas silviculturais; e a terceira no período de 2000 em diante, em que se passou a utilizar os clones e houve grande avanço na mecanização.

Também, deve se observar que os avanços do setor florestal foram influenciados pela implantação dos novos cursos de Engenharia Florestal no país. Segundo Brasil (2002), a formação de mão de obra especializada foi determinada, inicialmente, pela necessidade de dar suporte técnico ao desenvolvimento do setor florestal. Essa ênfase, aliada aos esforços públicos e privados de fomento à pesquisa, e o programa de incentivos fiscais ao reflorestamento foram responsáveis pelo desenvolvimento de eficiente silvicultura intensiva de plantações florestais de rápido crescimento e de um parque industrial de celulose e papel.

\section{CONCLUSÕES}

Nas décadas de 1960 e 70, o efeito produtividade foi o que mais contribuiu para o crescimento da produção de celulose de fibra curta. Os principais fatores que contribuíram foram o crescimento dos estudos de melhoramento genético e a introdução de novas procedências, bem como as políticas públicas e os incentivos fiscais.

Na década de 1980, obteve-se menor crescimento da produção em razão, principalmente, da crise e do

Revista Árvore, Viçosa-MG, v.36, n.6, p.1119-1128, 2012 
término dos incentivos fiscais. Já na década de 1990 as principais indústrias passaram a produzir visando ao mercado internacional, o que acarretou a expansão dos plantios de eucalipto.

Nos anos 2000, apesar de ter sido o período em que o reflorestamento mais cresceu, o efeito produtividade foi maior devido à introdução dos clones, aos avanços na mecanização e, também, ao déficit de reflorestamentos que existiu no final da década de 1990.

No geral, tem-se que, de 1960 a 2007, o principal fator que explicou o crescimento da produção de celulose foi a produtividade. Entretanto, o baixo valor para o efeito área foi devido ao fato de sua expansão só ter começado na década de 1990. Também, destaca-se que os reflorestamentos no Brasil são muito recentes, em comparação com os de outros países. Mesmo assim, o segmento conseguiu tornar-se competitivo, tanto no mercado nacional quanto no internacional.

\section{REFERÊNCIAS}

ALMEIDA, P. N. A. Fontes de crescimento e sistemas produtivos da orizicultura no Mato Grosso. 2003. 213f. Dissertação (Mestrado em Economia Aplicada) - Escola Superior de Agricultura "Luiz de Queiroz", Piracicaba, 2003.

ALVES, L. R. A.; SHIKITA, P. F. A. Fontes de crescimento das principais culturas do Paraná(1981 - 1999). Revista Paranaense, n.101/ p.17-32, 2001.

\section{ASSOCIAÇÃO BRASILEIRA DE CELULOSE E} PAPEL - BRACELPA. Relatório estatístico anual 2007/2008. Disponível em: <http:// www.bracelpa.org.br/bra/estatisticas/index.html>. Acesso em: 03 set. 2009.

BANCO NACIONAL DO DESENVOLVIMENTO BNDES, 1996. A trajetória de crescimento dos principais produtores brasileiros de papel e celulose - 1970/94. Disponível em: <http://www.bndes.gov.br/SiteBNDES/export/ sites/default/bndes_pt/Galerias/Arquivos/ conhecimento/bnset/bndeset3.pdf>. Acesso em: 04 set. 2009.
BRASIL. Ministério da Ciência e da Tecnologia. Ciência e tecnologia no setor florestal brasileiro: diagnostico prioridade, e modelos de financiamento: síntese. Piracicaba: 2002. 176p.

CAMPOS, R.T. 1991. Efeitos do ataque do bicudo na cotonicultura do semi-árido cearense. 1991. 160p. Tese (Doutorado) Universidade Federal de Pernambuco, Recife, 1991.

CARvalho, A. D. F. Histórico do melhoramento genético de eucalipto no Brasil. Piracicaba: Escola Superior de Agricultura “Luiz de Queiroz", 2000. Disponível em: <http://www.genetica.esalq.usp.br/pub/ seminar/ADFCarvalho-200602-Resumo.pdf $>$ Acesso em: 19 out. 2009.

FILGUEIRAS, G. C. Crescimento agrícola no estado do Pará e a ação de políticas públicas: Avaliação pelo método shift-share. 2002. 162f. Dissertação (Mestrado em Economia) - Universidade da Amazônia, Belém, 2002.

HILGEMBERG, E. M.; BACHA, C. J. C. A evolução da indústria brasileira de celulose e sua atuação no mercado mundial. Análise Econômica, v.19, n.36, p.67-92, 2001.

JUVENAL, T. L.; MATOS, R. L. G. O setor de celulose e papel. BNDES, 2002. Disponível em: <http://www.bndes.gov.br/SiteBNDES/bndes/ bndes_pt/Institucional/Publicacoes/ Consulta_Expressa/Tipo/Livro/200212_17.html > Acesso em: 08 out. 2009

MOntebello, A. E. S. Análise da evolução brasileira de celulose no período de 1980 a 2005. 2006. 114f. Dissertação (Mestrado em Economia Aplicada) - Escola Superior de Agricultura "Luiz de Queiroz", Piracicaba, 2006.

MOURA, B. M. Um indicador de desempenho para seleção de ativos das empresas de celulose e papel no mercado financeiro. 2008. 102f. Dissertação (Mestrado em Ciências Florestais) - Universidade de Brasília, Brasília, 2008.

PIZZOL, S. J. S.; BACHA, C. J. C. Evolução, estrutura e desafios da indústria de celulose no Brasil. Preços Agrícolas, v.12, n.137/ p.3-13, 1998.

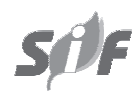

Revista Árvore, Viçosa-MG, v.36, n.6, p.1119-1128, 2012 
REIS, S. M.; CAMPOS, R. T. Efeitos da taxa de câmbio sobre os preços do cacau. In: CONGRESSO BRASILEIRO DE ECONOMIA E SOCIOLOGIA RURAL, 8., Poços de Calda, 1998. Anais... Brasília: SOBER, 1998. v.2. p.89-100.

SOARES, N. S. et al. Análise do mercado brasileiro de celulose, 1969-2005. Revista Árvore, v.33, n.3, p.563-573, 2009.

SOTO, B. F. A. Da indústria do papel ao complexo florestal no Brasil: o caminho do corporativismo tradicional ao neocorporativismo. 1992. 298f. Tese (Doutorado em Economia) Universidade de Campinas, Campinas, 1992.
SOUZA, A. N. Estudo econômico da reforma de povoamentos de Eucalyptus spp.- O caso do progresso tecnológico. 1999. 140f. Dissertação (Mestrado em Ciência Florestal) - Universidade Federal de Lavras, Lavras, 1999.

VALVERDE, S. R.; SOARES, N. S.; SILVA, M. L. Desempenho das exportações brasileiras de celulose. Revista Árvore, v.30, n.6, p.10171023, 2006

ZAEYEN, A. Estrutura e desempenho do setor de papel e celulose no brasil. 1986. 99f. Dissertação (Mestrado em Economia) Universidade Federal do Rio de Janeiro, Rio de Janeiro, 1986. 